\title{
PENGARUH PASANGAN DINDING BATA PADA RESPON DINAMIK STRUKTUR GEDUNG AKIBAT BEBAN GEMPA
}

\author{
Himawan Indarto ${ }^{1}$, Bambang Pardoyo ${ }^{2}$, Nur Fahria R. ${ }^{3}$, Ita Puji L. ${ }^{4}$ \\ ${ }^{1,2)}$ Dosen Teknik Sipil Universitas Diponegoro - Email : himawan.indarto@gmail \\ ${ }^{3,4)}$ Mahasiswa Teknik Sipil Universitas Diponegoro
}

\begin{abstract}
For analysis purpose, the model system of structure is created as open frame structure rather than massive structure. However, the brick wall will affect to the behavior of the dynamic response when the earthquake induces the structure. The results of structural analysis by time history method using El-Centro earthquake, it reveales a significant difference of base shear between two types of structural model: (i) brick wall structure and (ii) non-brick wall structure. The base shear exists on the brick wall structure 20 percent greater than non-brick wall structure. Therefore, a structure without brick wall will be more irressistant due to the earthquake. The structural analysis using static equivalent method as point out in Standard of Earthquake Resistant for Building and Non Building (SNI 03-1726-2012) revealed that earthquake distribution loads relatively equal for brick wall structure and non-brick wall structure. The difference of earthquake load approximately 10 percent among two type of structure. Thus, it could be concluded that static equivalent method is more reliable to estimate the earthquake load of the structure rather than other method. This research suggests that in the structural design practicality, the effect of brick wall should be considered as a part of the structural analysis model.
\end{abstract}

Keywords : brick wall, time history analysis, base shear

\begin{abstract}
Abstrak: Untuk keperluan analisis, sistem struktur biasanya dimodelkan sebagai struktur rangka terbuka, dimana hanya elemen-elemen struktur yang terbuat dari material beton saja yang disusun didalam pemodelan struktur. Adanya pasangan dinding bata pada sistem struktur akan mempengaruhi perilaku dari respon dinamik struktur pada saat terjadi gempa. Dari hasil analisis struktur dengan Metode Riwayat Waktu (Time History Analysis) menggunakan gempa El-Centro, didapatkan perbedaan nilai base shear yang cukup signifikan antara struktur dengan dinding bata yang dipasang monolit dengan struktur tanpa dinding bata. Base shear yang terjadi pada struktur dengan dinding bata lebih besar $20 \%$ dibandingkan dengan beban base shear yang terjadi pada struktur tanpa dinding bata. Jika hal ini tidak diperhatikan pada saat perencanaan struktur, maka struktur akan lebih mudah rusak jika terjadi gempa. Dari hasil analisis struktur dengan Metode Statik Ekivalen sesuai yang tercantum di dalam Tata Cara Perencanaan Ketahanan Gempa Untuk Struktur Gedung dan Non Gedung (SNI 03-1726-2012), didapatkan nilai distribusi beban gempa pada struktur gedung yang relative sama besar untuk bangunan dengan dinding bata dan tanpa dinding bata. Perbedaan besarnya distribusi gaya gempa untuk bangunan dengan dan tanpa dinding bata, kurang dari $10 \%$. Dengan demikian dapat disimpulkan bahwa Metode Statik Ekivalen ini cukup aman digunakan untuk memperkirakan beban gempa yang bekerja pada struktur.
\end{abstract}

Kata kunci : Pasangan dinding bata, Analisis Riwayat Waktu, base shear

\section{PENDAHULUAN}

Bangunan gedung dengan pasangan dinding bata banyak sekali dijumpai di kotakota besar di Indonesia. Pada umumnya bangunan jenis ini banyak digunakan sebagai bangunan rumah tinggal, bangunan perkantoran, dan bangunan ruko.

Pada umumnya, pasangan dinding bata yang ada pada bangunan, tidak diperhitungkan di dalam perencanaan struktur, sehingga pengaruh dari pasangan dinding bata terhadap kekuatan dan kekakuan struktur tidak diperhitungkan di dalam analisis dan desain struktur. Pasangan dinding bata dianggap hanya sebagai beban gravitasi saja, dan keberadaannya diasumsikan tidak mempengaruhi kekuatan dan kekakuan dari sistem struktur bangunan.

Struktur bangunan gedung dengan pasangan dinding bata mempunyai kekakuan struktur yang besar. Ditinjau dari aspek kegempaan, struktur bangunan dengan 
kekakuan struktur yang besar mempuyai perilaku kegempaan yang buruk. Semakin besar kekakuan dari bangunan maka akan semakin besar pula beban gempa yang akan bekerja pada struktur bangunan. Pengalaman terjadinya gempa-gempa besar di Indonesia telah membuktikan bahwa, banyak kerusakan yang terjadi pada struktur-struktur bangunan yang menggunakan pasangan dinding bata sebagai penyekat ruang. Dibawah ini ditampilkan kerusakan yang terjadi pada dinding bangunan akibat gempa.

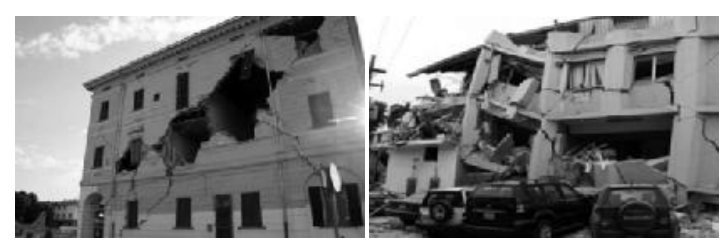

Gambar 1. Kerusakan pada dinding bangunan akibat gempa

\section{PENGARUH DINDING BATA PADA \\ STRUKTUR}

Karena dinding bata biasanya dipasang di tempat-tempat yang cukup luas pada bangunan gedung, maka pengaruhnya perlu diperhitungkan di dalam analisis struktur. Beberapa pengaruh dari adanya pasangan dinding bata pada sistem struktur bangunan gedung adalah :

a. Periode getar dari sistem struktur akan menjadi lebih pendek, sehingga akan memperbesar beban gempa yang bekerja pada bangunan. Distribusi dari gaya geser pada kolom-kolom bangunan kemungkinan akan berubah, sehingga tulangan yang diperhitungkan akan berbeda dengan yang telah direncanakan semula.

b. Penempatan pasangan dinding bata yang tidak simetris pada bangunan, akan menyebabkan momen puntir / torsi pada sistem struktur.

c. Terjadinya konsentrasi gaya-gaya dalam pada sistem struktur, jika pasangan dinding bata ditempatkan tidak beraturan di sepanjang ketinggian bangunan.

\section{METODE PENELITIAN}

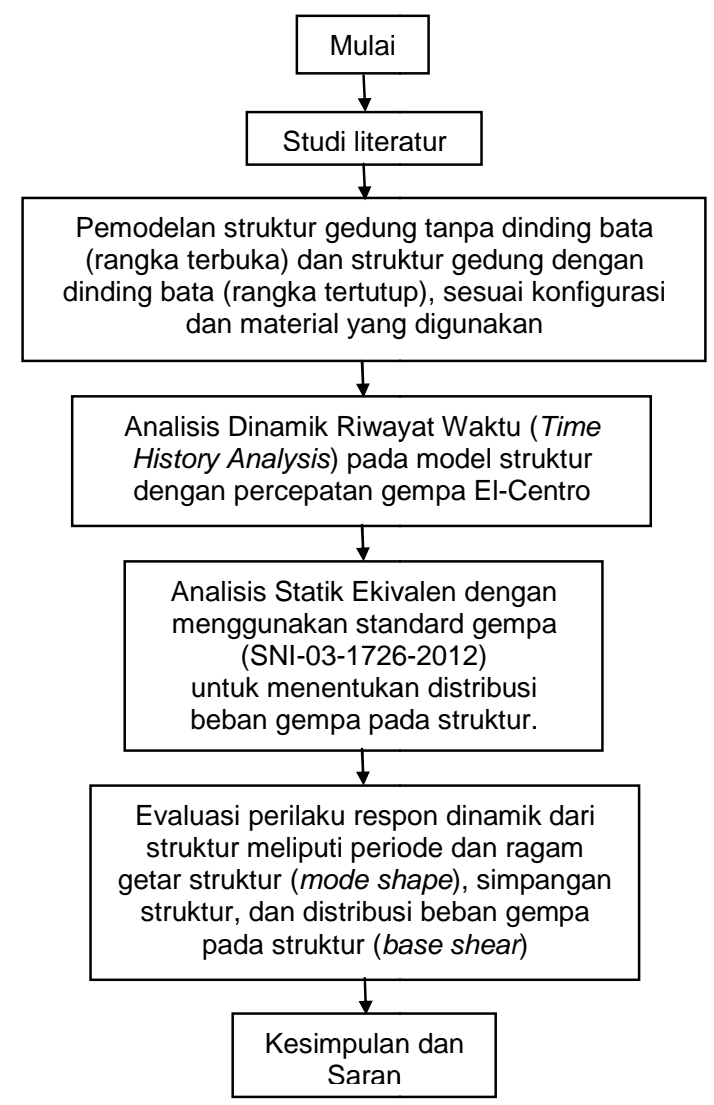

Gambar 2. Diagram Alir Penelitian

\section{ANALISIS DINAMIK RIWAYAT WAKTU}

Untuk mengetahui pengaruh pasangan dinding bata pada struktur rangka beton akibat beban gempa, dilakukan analisis dinamik riwayat waktu (time history analysis) dari 4 model struktur dengan menggunakan data masukan berupa percepatan gempa El-Centro (Gambar 3). Evaluasi dinamik riwayat waktu pada struktur meliputi besarnya beban gempa pada dasar bangunan (base shear), dan 
besarnya simpangan horisontal (displacement) pada atap bangunan.

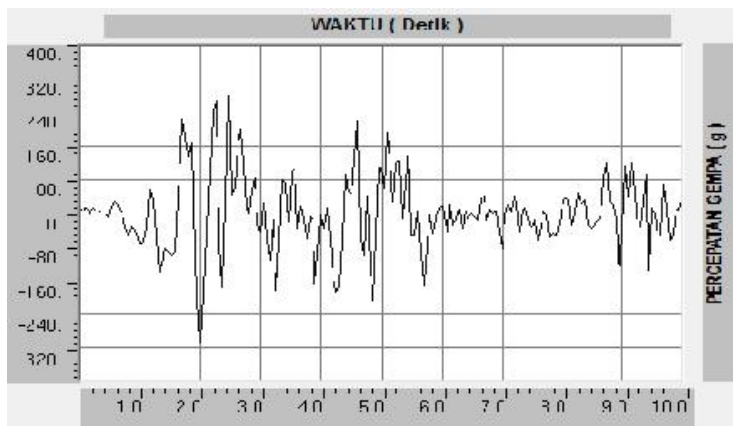

Gambar 3. Percepatan gempa El-Centro

Bangunan gedung yang dianalisis pada penelitian ini merupakan bangunan rumahtoko ( ruko ) 4 lantai yang terbuat dari rangka beton bertulang dengan pasangan dinding bata tebal $15 \mathrm{~cm}$. Dimensi kolom adalah

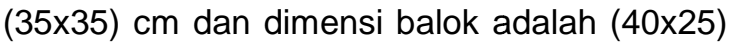
$\mathrm{cm}$. Karakteristik bahan beton dan pasangan bata seperti dicantumkan pada Tabel 1.

Tabel 1. Karakteristik Bahan Struktur

\begin{tabular}{lcc}
\hline Karakteristik Bahan & Beton & $\begin{array}{c}\text { Pasangan } \\
\text { Bata }\end{array}$ \\
\hline $\begin{array}{l}\text { Modulus elastisitas } \\
(\mathrm{kg} / \mathrm{cm} 2)\end{array}$ & 210000 & 32000 \\
\hline Berat jenis $(\mathrm{kg} / \mathrm{m} 3)$ & 2400 & 1700 \\
\hline
\end{tabular}

Model struktur yang ditinjau di dalam analisis riwayat waktu terdiri dari 4 konfigurasi struktur, sebagai berikut (Tabel 2):

Tabel 2. Konfigurasi Model Struktur

\begin{tabular}{cl}
\hline $\begin{array}{c}\text { Model } \\
\text { Struktur }\end{array}$ & \multicolumn{1}{c}{ Konfigurasi Struktur } \\
\hline Struktur-A & $\begin{array}{l}\text { Rangka beton dengan pasangan dinding } \\
\text { bata penuh, monolit }\end{array}$ \\
\hline Struktur-B & $\begin{array}{l}\text { Rangka beton dengan pasangan dinding } \\
\text { bata sebagian }\end{array}$ \\
\hline Struktur-C & $\begin{array}{l}\text { Rangka beton dengan pasangan dinding } \\
\text { bata, tidak monolit }\end{array}$ \\
\hline Struktur-D & $\begin{array}{l}\text { Rangka beton bertulang tanpa pasangan } \\
\text { dinding bata. }\end{array}$ \\
\hline
\end{tabular}

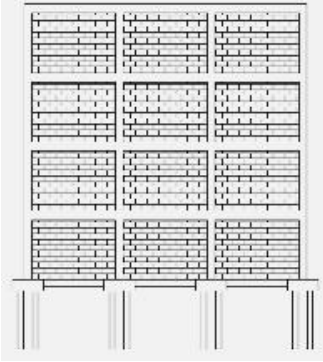

A

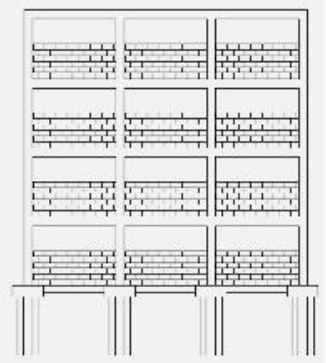

B
Gambar 4a. Model Struktur-A Gambar 4b. Model Struktur-B
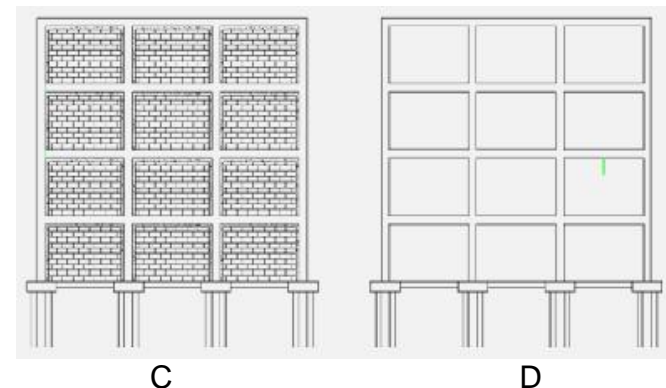

Gambar 4c. Model Struktur-C Gambar 4d. Model Struktur-D

Dari hasil analisis dinamik riwayat waktu (time history analysis) dari 4 model struktur dengan menggunakan data masukan berupa rekaman percepatan gempa El-Centro, didapatkan hasil beban gempa di dasar bangunan (base shear), seperti ditunjukkan pada Gambar 5.

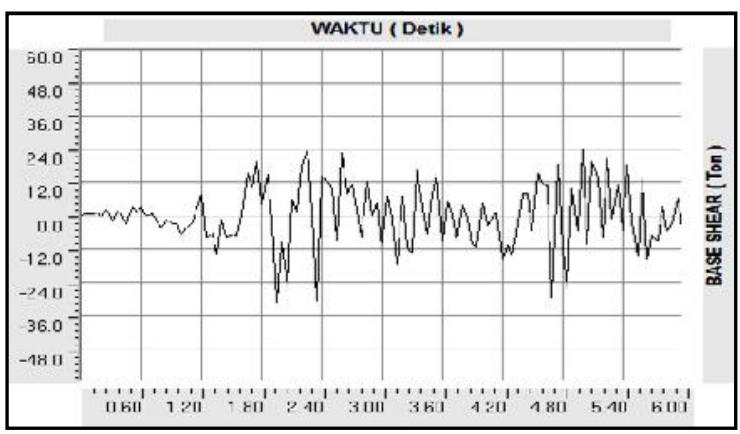

Gambar 5a. Beban gempa di dasar bangunan (base shear) Struktur-A ( base shear maksimum = 31,7 ton ) 


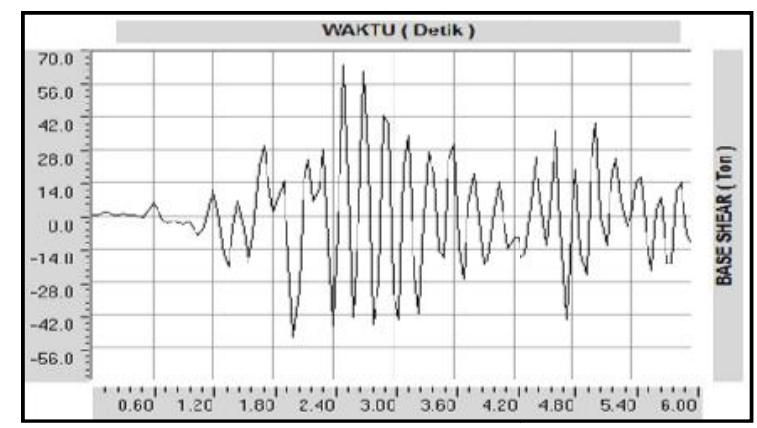

Gambar 5b. Beban gempa di dasar bangunan (base shear) Struktur-B ( base shear maksimum = 64,4 ton )

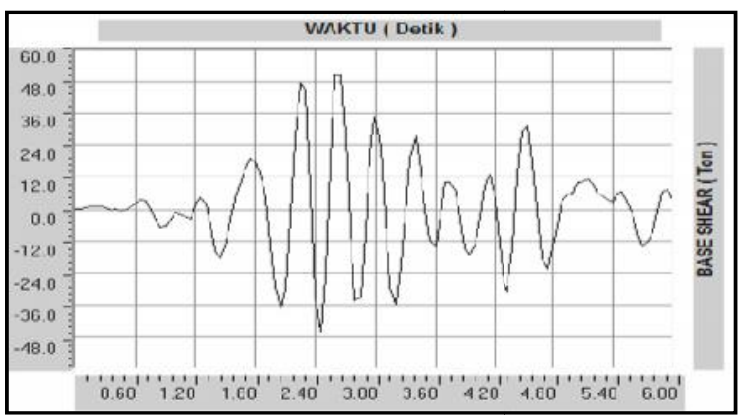

Gambar 5c. Beban gempa di dasar bangunan (base shear) Struktur-C (base shear maksimum = 50,0 ton )

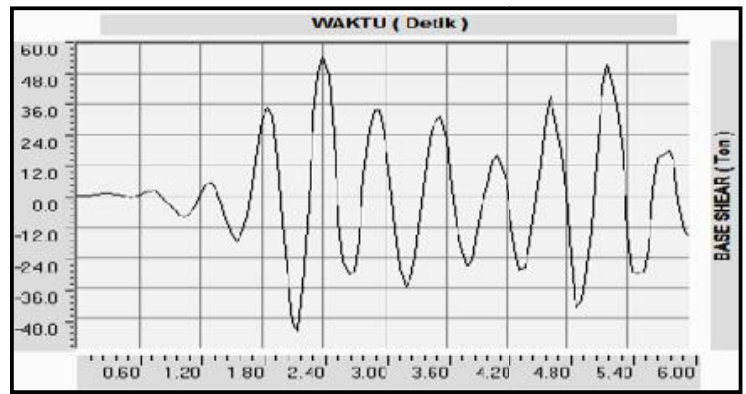

Gambar 5d. Beban gempa di dasar bangunan (base shear) Struktur-D ( base shear maksimum = 54,7 ton )

Tabel 3. Hasil Analisis Dinamik Riwayat Waktu Pada Model Struktur

\begin{tabular}{lcccc}
\hline \multirow{2}{*}{ Keterangan } & \multicolumn{4}{c}{ Model Struktur } \\
\cline { 2 - 5 } & $\begin{array}{c}\text { Struktur } \\
\text { A }\end{array}$ & $\begin{array}{c}\text { Struktur } \\
\text { B }\end{array}$ & $\begin{array}{c}\text { Struktur } \\
\text { C }\end{array}$ & $\begin{array}{c}\text { Struktur } \\
\text { D }\end{array}$ \\
\hline $\begin{array}{l}\text { Periode Getar } \\
\text { (detik) }\end{array}$ & 0,11 & 0,21 & 0,36 & 0,55 \\
\hline $\begin{array}{l}\text { Simpangan } \\
\text { (cm) }\end{array}$ & 0,20 & 1,30 & 3,70 & 9,20 \\
\hline $\begin{array}{l}\text { Base Shear } \\
\text { (ton) }\end{array}$ & 31,7 & 64,4 & 50,0 & 54,7 \\
\hline
\end{tabular}

Hasil analisis riwayat waktu dari 4 model struktur dengan menggunakan gempa ElCentro, dicantumkan pada Tabel 3.

\section{ANALISIS STATIK EKIVALEN}

Untuk mengetahui besarnya distribusi beban gempa pada struktur beton dengan pasangan dinding bata, dilakukan Analisis Statik Ekivalen pada keempat model struktur sesuai dengan standar gempa yang berlaku di Indonesia yaitu Tata Cara Perencanaan Ketahanan Gempa Untuk Struktur Gedung dan Non Gedung (SNI 03-1726-2012).

Untuk keperluan analisis dan desain struktur bangunan gedung digunakan model struktur 2 dimensi. Balok-balok dan kolomkolom pada struktur bangunan dimodelkan dengan menggunakan elemen Frame 2D, sedangkan pasangan dinding bata dimodelkan sebagai elemen Shell. Analisis statik dan dinamik dari struktur menggunakan software SAP2000.

Pembebanan yang ditinjau bekerja pada struktur rangka gedung terdiri dari beban mati, beban hidup dan beban gempa. Beban mati yang diperhitungkan pada struktur terdiri dari beban akibat berat sendiri pelat, balok dan kolom. Beban akibat penutup lantai, plafond, penggantung, dan beban finishing diperhitungkan sebesar $75 \mathrm{~kg} / \mathrm{m} 2$. Beban dinding bata diperhitungkan sebesar $250 \mathrm{~kg} / \mathrm{m}$ untuk setiap 1 meter tinggi. Berat jenis beton diperhitungkan sebesar $2400 \mathrm{~kg} / \mathrm{m} 3$, dan modulus elastisitas beton diperhitungkan sebesar : $E=200000 \mathrm{~kg} / \mathrm{cm} 2$

Sesuai dengan standar pembebanan yang berlaku di Indonesia, yaitu Beban Minimum Untuk Perancangan Bangunan Gedung Dan Struktur Lain (SNI 03-1727- 
2013), besarnya beban hidup pada gedung Ruko akibat hunian atau penggunaan ruangan diperhitungkan sebesar $250 \mathrm{~kg} / \mathrm{m} 2$. Untuk pelat atap beban hidup yang bekerja diperhitungkan sebesar $100 \mathrm{~kg} / \mathrm{m} 2$.

Distribusi beban gempa pada tiap lantai dari keempat model struktur yang dihitung dengan Metode Statik Ekivalen, dicantumkan pada Tabel 4 .

Tabel 4. Distribusi Beban Gempa Pada Struktur (Metode Statik Ekivalen)

\begin{tabular}{ccccc}
\hline \multirow{2}{*}{ Lantai } & \multicolumn{4}{c}{ Distribusi Beban Gempa (ton) } \\
\cline { 2 - 5 } Struktur & $\begin{array}{c}\text { Struktur- } \\
\text { A }\end{array}$ & $\begin{array}{c}\text { Struktur- } \\
\text { B }\end{array}$ & $\begin{array}{c}\text { Struktur- } \\
\text { C }\end{array}$ & $\begin{array}{c}\text { Struktur- } \\
\text { D }\end{array}$ \\
\hline Lantai 4 & 4,6 & 4,6 & 4,3 & 4,5 \\
\hline Lantai 3 & 4,1 & 4,1 & 3,8 & 3,8 \\
\hline Lantai 2 & 2,7 & 2,7 & 2,5 & 2,4 \\
\hline Lantai 1 & 1,5 & 1,5 & 1,3 & 1,2 \\
\hline
\end{tabular}

\section{KESIMPULAN DAN SARAN}

\section{Kesimpulan}

a. Dari hasil analisis struktur dengan Metode Riwayat Waktu (Time History Analysis) menggunakan gempa El-Centro, didapatkan perbedaan nilai beban gempa di dasar bangunan (base shear) yang cukup sigmifikan antara bangunan dengan dinding bata yang dipasang monolit dengan bangunan tanpa dinding bata. Besarnya perbedaan nilai dari base shear antara kedua bangunan ini kurang lebih $20 \%$.

b. Dari hasil analisis struktur dengan Metode Riwayat Waktu, didapatkan perbedaan nilai base shear antara bangunan dengan dinding bata yang dipasang tidak monolit dengan bangunan tanpa dinding bata, sebesar kurang lebih $10 \%$. c. Dari hasil analisis struktur terhadap gempa dengan Metode Statik Ekivalen sesuai yang tercantum di dalam Tata Cara Perencanaan Ketahanan Gempa Untuk Struktur Gedung dan Non Gedung (SNI 03-1726-2012), didapatkan nilai distribusi beban gempa yang relatif sama besar untuk bangunan dengan dinding bata dan tanpa dinding bata. Perbedaan besarnya distribusi gaya gempa untuk bangunan dengan dan tanpa dinding bata kurang dari $5 \%$.

\section{Saran}

a. Untuk mengurangi pengaruh beban gempa pada bangunan, dinding bata sebaiknya dipasang tidak monolit pada struktur rangka beton. Hal ini bertujuan untuk mengurangi kekakuan dari sistem struktur rangka beton, sehingga beban gempa yang bekerja pada sistem struktur dapat direduksi.

b. Jika di dalam perencanaan struktur pengaruh dinding bata tidak diperhitungkan di dalam analisis, maka di sarankan untuk menggunakan analisis Metode Statik Ekivalen sesuai yang ada di dalam Tata Cara Perencanaan Ketahanan Gempa Untuk Struktur Gedung dan Non Gedung (SNI 03-17262012).

\section{DAFTAR PUSTAKA}

Badan Standarisasi Nasional (BSN), SNI 031726-2012, Tata Cara Perencanaan Ketahanan Gempa Untuk Struktur Gedung dan Non Gedung

Badan Standarisasi Nasional (BSN), SNI 032847-2013, Persyaratan Beton Struktural Untuk Bangunan Gedung 
Badan Standarisasi Nasional (BSN), SNI 031727-2013, Beban Minimum Untuk Perancangan Bangunan Gedung Dan Struktur Lain

R.W. Cloud, J. Penzien, 1995. Dynamics Of Structure. Computer \& Structure Inc., University Ave. Berkeley, USA

M. Wakabayashi, 1986. Design Of Earthquake Resistant Buildings. Mc. Graw Hill, New York 